\title{
Land-sea interactions: case studies from the Baltic Sea Region
}

\author{
Leila Neimane ${ }^{1, *}$ \\ ${ }^{1}$ University of Latvia, Faculty of Law, Institute of Legal Science, Raina blvd. 19, LV-1586 Riga, \\ Latvia
}

\begin{abstract}
Research background: Nowadays, mainstream discussions on maritime spatial planning (MSP) are tightly intertwined with the discourse on governance for land-sea interactions or interface (LSI), using multi-scalar and cross-sectoral governance systems. At the same time, principles with legal rank need to be respected and applied in both MSP and LSI and their respective governance structures while putting coastal communities at the centre and taking into consideration the process of "maritimisation." In combination, these factors contribute to augmenting the pressure of competing uses both on land and sea in the frame of the Blue Economy. As an exemplary forerunner in the field of MSP, the Baltic Sea Region (BSR) and its case studies can provide a useful insight in this respect.

Purpose of the article: The aim is to identify and integrate the principles with legal rank of Effective Governance for sustainable development to be implemented through different LSI governance perspectives and in the framework of MSP and the Blue Economy, providing concise guidance as to their application through BSR case studies.

Methods: Preparation of this article involves applying traditional legal research methods (analysis and synthesis) and the results of maritime spatial plans and practical examples of pilot projects. Analysis includes the following techniques: descriptive, historical, special analytical and dogmatically comparable, including an analytical perspective of transnational environmental law. Synthesis is applied through the legally constructive method.

Findings \& Value added: Based on conclusions and lessons learned from BSR case studies, the article offers added value by structuring and improving knowledge and providing a basis for further theoretical discussion.
\end{abstract}

Keywords: Baltic Sea Region; Effective Governance; land-sea interactions; maritime spatial planning; One Space planning

JEL Classification: $K 32 ; O 21 ; R 11 ; R 12 ; R 58$

* Corresponding author: leila.neimane@1u.lv 


\section{Introduction}

Today, the decisive contribution of the oceans, seas, and coastal zones not only to protection of the environment but also to the future sustainability of all human beings and the planet is a well-known fact and matter of urgency, as evidenced, inter alia, by the United Nations (UN) -declared Decade (2021-2030) of Ocean Science for Sustainable Development.

Goal 14 of the UN Sustainable Development Agenda 2030 is "Life below Water" ("Conserve and sustainably use the oceans, seas and marine resources for sustainable development"). This is supported by specific targets related to ocean conservation, seas, and marine resources, including coastal zones, as well as targets related to capacity building and ocean governance. Against this background, the importance of maritime spatial planning (MSP) has significantly increased, and indeed is considered to be one of the most appropriate ways to ensure effective organization of use of the sea, not least achieving Sustainable Development Goal 14. This is evidenced by the application of MSP as an important, instrumental, and well-established policy tool in more than 75 countries around the world to promote and support more sustainable progress in the Blue Economy in line with changing policy settings and the demands of modern society.

Both use of the sea and use of coastal areas are constantly intensifying since the coasts serve as staging locations for new and emerging maritime sectors while at the same time the pressure and burden on coastal areas and the marine environment continues to increase because of co-evolution (Schlüter et al., 2020). However, as indicated by the prominent MSP researcher Andrea Morf (VASAB Secretariat, 2021a): "There are still huge challenges to link the different planning systems over the shoreline, because [..] that is where in many countries the systems meet up but don't connect." So, because marine and coastal activities are frequently intertwined, understanding land-sea interactions (LSI) is crucial to delivering MSP successfully (VASAB Secretariat, 2021a). Against that background, this article aims at identifying and integrating the principles with legal rank of Effective Governance for sustainable development to be implemented through different LSI governance perspectives and in the framework of MSP and the Blue Economy, providing concise guidance on their application through case studies of the Baltic Sea Region (BSR).

\section{Methods}

Traditional legal research methods (analysis and synthesis) are used throughout the study. Methodologies used in the analysis include descriptive, historical, special analytical, and dogmatically comparative techniques, as well as an analytical perspective of transnational environmental law through selected governance approaches. The method of synthesis is used in a legally constructive manner. The study considers recent versions of maritime spatial plans in the BSR, cases of pilot projects and information provided during the $4^{\text {th }}$ Baltic MSP Forum, organised on 1-2 June 2021 and representing the MSP regional discussion platform.

Selected governance approaches are:

1) Evolutionary Governance to address the ever-increasing need for management of the sea and coastal areas and to offer a perspective on governance that prioritizes coevolution regarding continuous changes of interactions between actors, institutions, organizations, and paradigms, including power, knowledge, and narrative (Schlüter et al., 2020; O’Hagan et al., 2020; Van Assche et al., 2020);

2) Multi-level Governance as a "collaborative and cooperative way of innovation governance facilitated across all relevant governance levels within and beyond the borders of the governable territory in intersection with non-government stakeholders" (Anita Livija Rozenvalde, Ministry of Environmental Protection and Regional Development of Latvia) (VASAB Secretariat, 2021b); 
3) Departing from the widely established recognition of stakeholder participation as a prerequisite for increased legitimacy of the process and its outcomes, and "a democratic right of stakeholders" (Piwowarczyk et al., 2019, p. 103), "Effective governance for sustainable development" (Effective Governance) as a derivate of the well-known concept of "Good Governance" that is especially frequently used in administrative law and discourses on the rule of law, so that the principles that make it up enjoy legal rank. The concept of Effective Governance was developed by the UN Committee of Experts on Public Administration and endorsed by the UN Economic and Social Council (2018) and contains a set of principles, serving "a dual purpose: to outline an inclusive, collaborative process for building strong institutions at all levels and to enrich its policy advice on issues in governance and public administration, both with a view to strengthening evidence-based and action-oriented support for the implementation of the 2030 Agenda" (UN Committee of Experts on Public Administration, 2019). Since full realization of Sustainable Development Goals including Goal 14 "Life below Water" is dependent on the principles of Effective Governance (UN Economic and Social Council, 2018), consequently, this governance forms a part of a wider social sustainability understanding in the MSP process, integrating LSI.

\section{Results}

The principles of Effective Governance are grouped around three dimensions: Effectiveness, Accountability, and Inclusiveness, and apply to state institutions. Competence (1), sound policy making (2) and collaboration (3) are included in the Effectiveness dimension. Accountability comprehends integrity (4), transparency (5) and independent oversight (6). Inclusiveness is composed of such principles as leaving no one behind (7), nondiscrimination (8), participation (9), subsidiarity (10) and intergenerational equity (11). Each principle is described accordingly. For example, the competence principle means: "To perform their functions effectively, institutions are to have sufficient expertise, resources and tools to deal adequately with the mandates under their authority" (UN Economic and Social Council, 2018). Or, leaving no one behind is expressed in the following way: "To ensure that all human beings can fulfil their potential in dignity and equality, public policies are to take into account the needs and aspirations of all segments of society, including the poorest and most vulnerable and those subject to discrimination" (UN Economic and Social Council, 2018).

Because successful and meaningful implementation of these principles is required for full attainment of the Sustainable Development Goals and achieving their aspiration, the principles form an important component of the above-mentioned governance theories. In the framework of Evolutionary Governance, they could be classified and entitled as goal dependencies - "impacts of visions for the future on the current reproduction of governance" (Van Assche et al., 2020). Additionally, previous plans, policies, laws, and informal institutions heralding preferable future visions, including changes in the actor/institution configuration, are other examples of such goals (Van Assche et al., 2020; see also O'Hagan et al., 2020). Against this background, combining Evolutionary Governance, Multi-level Governance and Effective Governance, the author advocates use of principles with legal rank of Effective Governance in MSP, including evaluation of LSI and especially for the next MSP cycles.

Within the scattered and fragmented framework of MSP where "the sectoral approach and well-established habits in the area of granting competences to individual administrative authorities responsible for maritime affairs" continue to dominate (Pyc, 2019, p. 311), applying those principles to the state institutions responsible for MSP can support and 
improve decision-making and contribute to deliberative stakeholder platforms which are needed to ensure a MSP process which takes into account LSI and is "cyclical, holistic and prescribed on an a priori basis" (Jones et al., 2016, p. 61). Applying this approach in revision of maritime spatial plans would ensure that difficulties in maintaining transparency in the eyes of stakeholders are avoided.

However, this approach has its shortcomings, which require further in-depth analysis. From the methodological point of view, the question should be addressed as to how members of society who, for example, have not participated in or heard about MSP could express their opinions. In practice, there could be a relatively large number of such cases across many countries. So, as the first step, there would be a need to sift out people from the evaluation process who may not have an opinion on MSP and could not comment on the content of the principles of Effective Governance in this regard. However, such an exclusion would have undemocratic effects. Therefore, it should be considered how to inform the people involved in evaluating the MSP in an appropriate way so that they can give their opinion and judgement.

Another methodological issue would be how to integrate the principles of Effective Governance into ecosystem-based management frameworks since various approaches exist that could be applied, e.g., through sustainability assessment (Frederiksen et al., 2021), the social sustainability approach, used by Saunders et al. (2020) or during recurring evaluation of maritime spatial plans (more precisely in this case - the MSP process), operationalised by a third-party audit or responsible planning body in cooperation with stakeholders (Stelzenmüller et al., 2021). Last but not least, several options are available as to how these assessments could be carried out: quantitatively, or rather based on qualitative local community assessment, supplemented by the judgement of society at large and/or expertbased evaluation.

Despite these methodological uncertainties, at this stage, the main concern is to acknowledge the importance of applying Effective Governance principles in MSP, especially in relation to LSI, and the need to measure them since "development and systematisation of the impact assessment categories and related criteria within the economic, social, and environmental domain could provide important relevant support to the planning for sustainable use of marine space" (Frederiksen et al., 2021).

Additionally in relation to the MSP and LSI, several established and recognized processinherent principles need to be applied, such as the overarching principle of sustainable development, the ecosystem-based management (ecosystem approach) principle, the integrated management principle and the principle of transparency and coordination of MSP. Discussions about what Key Principles are included in ecosystem-based management (Long et al., 2015) and the character of their legal nature, content, and categorisation (Pyc, 2019) are still ongoing and form a part of more in-depth scientific work, based on practice and empirical evidence, in the future and taking into account co-evolution aspects. In particular, this is true in relation to new emerging MSP principles such as the multi-use principle, the principle of prioritization of activities, the principle of hierarchy of activities, and the principle of dimensionality. What is important to underline here is that there is a need to look for the interconnection between specific MSP principles and Effective Governance principles with special emphasis on their synergistic and reinforcing effect.

\section{Discussion}

In the EU, after establishment of the Integrated Maritime Policy in 2007, the next step was adoption of the Marine Strategy Framework Directive (2008/56/EC) (MSFD) introducing the notion of "good environmental status" and a framework for implementing an ecosystembased approach grounded on a longer term-view and "hard" sustainability (Jones et al., 2016). 
This was followed by the Blue Growth Strategy in 2012 and Directive 2014/89/EU establishing a framework for MSP (MSPD) and forming the legislative basis of the Integrated Maritime Policy, thus grounded on a shorter-term view and "soft sustainability", and promoting maritime economic development (Jones et al., 2016).

The characteristic dichotomy between "hard sustainability" and "soft sustainability" of the two "framework" directives has had a considerable impact on the development of MSP practice in the EU Member States (Piwowarczyk et al., 2019) which "appear to be functioning more on an antagonistic than synergistic basis" (Jones et al., 2016, p. 262). In the spirit of MSFD, marine spatial planning is viewed as a mechanism for achieving "good environmental status", while in turn, MSPD positions maritime spatial planning as a tool for integration of different uses and promotion of Blue Growth (Jones et al., 2016).

As a result, at the EU and national levels, a certain schism persists between the goals of attaining renewable energy targets, safeguarding biodiversity, and "combating" climate change, on the one hand and, on the other, the wider goal of achieving sustainable development, especially when necessary to take into account "coastal condition" (O'Hagan et al., 2020; see also Jones et al., 2016). Prioritising one use over another in initial MSP efforts through case studies at the European level showed a subjective impact upon the potential efficiency evaluation of the MSP depending on whether strong environmental status, Blue Growth, renewable energy capacity, traditional activities, and so on are given actor's top concerns (Jones et al., 2016).

On a national scale, it can be argued that the legislation applicable to planning and management of the marine environment in each EU country contains more than 200 instruments at international, regional, EU and national levels (O'Hagan et al., 2020). As a result of events or instruments with a much broader scope, rather narrowly focused policy and legal instruments emerge and, in some cases, the overall goal of natural resource management and/or sector-specific action can become lost in the weeds of updated law (O'Hagan et al., 2020). Additionally, regardless of common issues and Europe-wide policy agendas, Member States retain authority over land-use planning, property rights and critical aspects of key consenting processes for marine development (O'Hagan et al., 2020). As a result, the form and structure of MSP vary by country (ESPON, 2020) while at the same time LSI experience differs greatly between countries and sea basins (no uniform "one-size-fitsall" approach to detecting and managing LSI issues) (Morf et al., 2019; Kidd et al., 2019, 2020; Van Assche et al., 2020).

Against this background, finding a balance between new sea uses and the interests of local people, combining nature protection and social well-being (Kristine Veidemane, Baltic Environmental Forum - Latvia) (VASAB Secretariat, 2021a) remains a daunting task. As discussed above, historically, MSP emerged from a conservation-centric approach, especially in the EU, and was later supplemented by the Blue Economy perspective (O'Hagan et al., 2020), whereas the social dimension of the sustainability of MSP (Frederiksen et al., 2021; Saunders et al., 2020) and LSI (Kidd et al., 2019) has remained underrepresented. To overcome this drawback, there is a need for social sciences to interconnect, integrate and combine with natural sciences and technical aspects, including raising awareness not only of coastal communities but of society at large regarding MSP and LSI (Andrea Morf, Swedish Institute for the Marine Environment / Nordregio) and inter alia using the approach of sharing best practice, success stories and good examples from other parts of the world (Tymon Zielinski, Institute of Oceanology, Polish Academy of Sciences) (VASAB Secretariat, 2021a). 


\subsection{Regulatory context of land-sea interactions}

Since land and marine activities are frequently intertwined, as part of MSPD, LSI were formally brought into European legislation though the legislative spirit of the Directive (Recitals 9, 16, 18) in connection with the operative provisions establishing LSI as one of the MSP's minimum requirements (Articles 4(2), 4(5), 6(2)(a)).

According to Article 7, paragraph 1, of the MSPD, Member States may consider LSI through the MSP process or through other formal or informal processes such as the preexisting and longer-standing concept of Integrated Coastal Zone Management (ICZM) (Van Assche et al., 2020; Morf et al., 2019; Kidd et al., 2019, 2020; European Commission, 2017) in which case the outcome must be reflected in maritime spatial plans. ICZM's existence dates back to the 1990s and in the EU was promoted by different initiatives, particularly the EU ICZM recommendations of $2002(2002 / 413 / E C)$ and several pilot projects. As a result, in some cases the development of MSP instruments is linked to the specific experience of coastal states gained through ICZM (Pyc, 2019).

Paragraph 2 of Article 7 (see also Article 6(2), c)) of the MSPD states that, in the framework of MSP, Member States should strive to promote coherence of the resulting maritime spatial plan or plans with other relevant processes. It is important to note that in Recital 18 of the Directive, along with other essential components of MSP (e.g., information collection, implementation, revision or updating, and monitoring of implementation), the LSI together with best available knowledge is a particularly emphasized aspect, thus underscoring its relevance in the MSP process.

The MSPD features the LSI as a political compromise following objections by some Member States that ICZM falls under national competence, so that reference to ICZM in the Directive would contradict sovereign rights over territorial waters (Morf et al., 2019), and the competence of spatial planning on land of the Member States, thus infringing the principle of subsidiarity (O'Hagan et al., 2020; see also Soininen \& Hassan, 2019). Therefore, Recital 17 of the MSPD states that "if Member States apply terrestrial planning to coastal waters or parts thereof, this Directive should not apply to those waters." The EU regulation features LSI in the MSPD, considering existing differences between the concepts of the ICZM and LSI (Table 1) and one can agree that, since introduction of MSP, the prominence of the ICZM has faded (O’Hagan et al., 2020).

Table 1. General commonalities and differences between LSI and ICZM.

\begin{tabular}{|c|c|c|}
\hline & LSI & ICZM \\
\hline Problems addressed & \multicolumn{2}{|c|}{$\begin{array}{c}\text { Arising from fragmented governance in } \\
\text { coastal and marine settings }\end{array}$} \\
\hline Principles applied & \multicolumn{2}{|c|}{ Similar, e.g., stakeholder participation } \\
\hline Regulation of spheres & $\begin{array}{c}\text { Nature conservation, coastal flooding and } \\
\text { defence and local economic development }\end{array}$ \\
\hline $\begin{array}{c}\text { Collaboration between } \\
\text { civil society, businesses } \\
\text { and government }\end{array}$ & Yes & Yes \\
\hline $\begin{array}{c}\text { Inclusion of land-based } \\
\text { activities, areas and } \\
\text { bodies }\end{array}$ & Yes & $\begin{array}{c}\text { Up to the high- } \\
\text { water mark }\end{array}$ \\
\hline Legal status & Statutory & $\begin{array}{c}\text { Voluntary } \\
\text { practice }\end{array}$ \\
\hline Resuirement & $\begin{array}{c}\text { Maritime spatial } \\
\text { plan or plans }\end{array}$ & $\begin{array}{c}\text { Strategies and } \\
\text { management } \\
\text { plans }\end{array}$ \\
\hline
\end{tabular}

Source: European Commission (2017) 
LSI per se entails complex and ever-shifting interactions between social-ecological considerations (e.g., eutrophication, sedimentation), socio-economic activity on land and at sea (Kidd et al., 2020) and socio-cultural concerns (Morf et al., 2019). Against this background, the significance of LSI in the context of MSP remains vague, making implementation problematic (Morf et al., 2019), also considering that MSP itself is "a highlevel generalisation" (Anu Printsmann, Tallinn University) (VASAB Secretariat, 2021a).

Discussions on the right approach to LSI have been ongoing for several years, in particular as to whether it is necessary to implement the division (disaggregation) of LSI elements or, to effectively handle LSI, there is a need for integrated "whole system" viewpoints and methodologies (Kidd et al., 2019). According to the European Commission (2017), several approaches are possible in addressing LSI in MSP. These include expanding on the experience of ICZM, harmonizing terrestrial and maritime spatial plans, and carrying out spatial planning on a land-sea scale.

Using the evidence collected by the preceding ESaTDOR project (2010-2013), the ESPON MSP-LSI project (2018-2019) advocated the "One Space" method (a governing model that includes both land and sea) for approaching the complexity of LSI within MSP and contributing to enhanced and more effective and efficient MSP processes. In this regard, Morf et al. (2019, p. 13) suggest that "One Space" planning might "begin with LSI scoping as a useful first stage, discussing the nature of LSI with relevant stakeholders and identifying critical issues for a more detailed examination. Analysis of critical LSI dimensions and their relevance to MSP and terrestrial planning would then serve as a basis for concrete one space planning." This territorial planning method can be essential in meeting the objectives for LSI outlined in the MSPD (ESPON, 2020).

\subsection{Approaches in the Baltic Sea Region}

The BSR is one of the elements of the Marine Region Concept introduced by the MSFD. The EU Strategy for the BSR (Commission of the European Communities, 2009) is the first of four macro-regional strategies in the EU and aims to strengthen co-operation between the countries bordering the Baltic Sea to address common challenges and benefit from common opportunities. As pointed out by the HELCOM-VASAB Working Group (see below) cochair Joacim Johannesson (VASAB Secretariat, 2021c), although the countries of the region use the same legislation in this area, implementation differs, so a common regional framework has the potential to deliver a number of benefits.

The BSR has been a forerunner in terms of accumulating common experience in MSP in a European context (Frederiksen et al., 2021) and developing pan-Baltic thinking in the field with special impetus on two interpenetrating and immanently linked notions such as integrative MSP and ecosystem-based MSP and transferring knowledge and know-how to the national level (Zaucha, 2014). MSP was first introduced in the BSR at the beginning of the 2000s with the BaltCoast project (2002-2006), formulating the concept of MSP and proposing basic MSP principles (Zaucha, 2014). Later, it was followed by the BaltSeaPlan project (2009-2012) which elaborated a vision of MSP development on a sea-wide scale, the Plan Bothnia project (2010-2012) during which necessary common minimum requirements for MSP worked out in BSR and the PartiSEApate project (2012-2014) through which a governance model for the BSR was prepared (Zaucha, 2014). At the policy level, development of MSP in the BSR is inextricably linked since 2001 to collaboration between these ministers known as Vision and Strategies for the Baltic Sea (VASAB) and the Baltic Marine Environment Protection Commission or Helsinki Commission (HELCOM). Since 2010, the work of the Joint HELCOM-VASAB Working Group has been highlighted as a noteworthy example of how countries may collaborate on a long-term basis to address LSI 
on a macro-regional scale, outlining that this provides a good model for other sea basins to follow (Kidd et al., 2019).

Respecting the deadline of March 31, 2021, for establishing the maritime spatial plans set out in Article 15, paragraph 3, of the MSPD, all countries in the BSR have approved their maritime spatial plans or are in the final stage of doing so (European MSP Platform, n.d.). In this respect, the situation here is significantly better than in other regions of the EU, where progress in adopting maritime spatial plans is relatively slower. In the BSR, several countries have reported that LSI considerations have been taken into account during the development of MSP (e.g., Finland, Latvia, Estonia) (European MSP Platform, n.d.). For example, as observed during the Pan Baltic Scope project (2018-2019), the Swedish planning system does not involve a formalized approach to LSI. The national approach to MSP takes a systems perspective, acknowledging that most uses might have LSI features. The overlapping of national MSP and local coastal planning is highlighted here as a means of guaranteeing a "planning continuum" (Morf et al., 2019). In Latvia, the law establishes the relationship between land and sea by mandating the MSP to consider functional links with land use (European MSP Platform, n.d.). However, remedies offered at the national level are insufficiently specific to be applied to local planning in all circumstances. For this reason, specific guidelines for implementing functional links in MSP have been created in the framework of the Pan Baltic Scope project (Ministry of Environmental Protection and Regional Development of the Republic of Latvia, 2019).

In Lithuania, a maritime spatial plan is being prepared as part of a comprehensive plan. Lithuanian practice evidences that the main areas of conflicting and competing interests (for example, port activities, protected areas, and residential areas) were situated along the coast rather than in the water (Donata Paulauskaite, Ministry of Environment of the Republic of Lithuania) (VASAB Secretariat, 2021b), and one might assume that the combination of land and sea planning through one plan can inter alia help to ensure better co-existence among different uses.

In Poland, MSP is supported by Maritime Policy, and sea space is also included in the Spatial Development Concept (a part of the Long-Term Development Strategy) (Zaucha, 2014). MSP legislation requires that, during preparation of a MSP plan, local spatial plans of coastal municipalities as well as the results of studies and spatial assessments relevant to coastal municipalities must be considered (European MSP Platform, n.d.), as occurred in the pilot plan for the western part of the Gulf of Gdansk (developed under the PlanCoast project (2006-2008)) and the pilot plan for the Pomeranian Bight (developed under the BaltSeaPlan project and including Denmark, Germany, Sweden, and Poland), both also being supplemented by stakeholder participation (Zaucha, 2014). Zaucha (2014, p. 40) points out: "In effect, Poland is one of a few countries worldwide that has achieved a high level of strategic integrity between marine and terrestrial spaces."

Among the BSR countries, only Germany and Lithuania have been making headway in gaining experience with preparing second-generation plans. Thus, one can agree that the BSR countries have only recently begun "to learn how integration challenges manifest themselves in the reality of planning and how these challenges can be addressed" (Piwowarczyk et al., 2019, p. 99).

The above-discussed "One Space" planning would mean, for example, developing a comprehensive plan, covering both land and sea (as in Lithuania) or extending MSP in coastal land or at least consideration of local spatial plans, results from studies and spatial assessments to coastal municipalities (following the Polish experience). This can be implemented using the experience of the Land-Sea-Act project (2019-2021), e.g., through including a terrestrial part of up to 10 kilometres in MSP (c.f. Southwestern Kurzeme case study in Latvia (Anda Ruskule, Baltic Environmental Forum - Latvia)) or using such innovative approaches as developing and maintaining small-craft harbours and landscape 
stewardship in Northern Estonia (Anu Printsmann, Tallinn University) (VASAB Secretariat, 2021a).

This approach would help to manage such situations when, for example, planning for offshore wind farms necessitates strategic sector-wide planning, whereas strategic allocation of space and infrastructure onshore is the responsibility of municipalities and regions, which frequently plan for population expansion (Morf et al., 2019). However, in practice, MSP often does not reach over the waterline, raising issues of "formal jurisdiction" and many discussions regarding LSI are limited to the coastal/marine landscape, as investigated in the Land-Sea-Act project's Gulf of Gdansk (Poland) case study (Tymon Zielinski, Institute of Oceanology, Polish Academy of Sciences) (VASAB Secretariat, 2021a). In this regard, since - according to Article 6, para. 3 of MSPD - maritime spatial plans should be reviewed at least every ten years (some countries, e.g., Estonia, Latvia, and Lithuania, have set an even shorter review period), this offers the possibility to adjust up-to-date governance arrangements that may be needed.

\section{Conclusions}

The first factor to be borne in mind is awareness-raising in regard to MSP and LSI issues both in coastal communities and in wider society. Considering the vast varieties of MSP and LSI across countries and regions, this approach includes not only having a sound legislative basis, use of scientific knowledge of natural sciences and considering the technical aspects, but also transfer of knowledge, exchange of experience, and sharing good practices.

The complexity of LSI within MSP can be approached using the "One Space" planning method that covers both land and sea and contributes to improved and more effective and efficient MSP processes. In a constantly changing governance context, "One Space" planning could imply creation of a comprehensive plan that covers both land and sea, or expansion of MSP to coastal territory, or at the very least consideration of local spatial plans, study results, and spatial assessments. Recurring evaluation of maritime spatial plans offers the possibility to customize them according to up-to-date governance arrangements.

Evolutionary Governance, Multi-level Governance and Effective Governance are approaches to ensuring meaningful inclusion of LSI in MSP and the effectiveness and efficiency of MSP. Evolutionary Governance through supporting the concept of "coevolution" is the most suitable in terms of grasping the complexities of the MSP and LSI to ensuring mutual influence and synergies between the theories of the two remits and ensure direction towards sustainable development. Principles with legal rank, having legal standing, which lie at the heart of Effective Governance, also play a significant role in the evolution of other governance systems. Their application to state institutions in charge of developing maritime spatial plans can help to assist and improve decision-making, as well as contributing to the deliberative stakeholder platforms that are required to ensure a circular process based on a priori prescription MSP that incorporates LSI. Additionally, there is the need to explore for connections between MSP specific concepts and Effective Governance principles, with a focus on their synergistic and reinforcing effects.

\section{Acknowledgements}

This work is an output of the research project and has been financially supported by specific support objective activity 1.1.1.2. "Post-doctoral Research Aid" of the Republic of Latvia (project No. 1.1.1.2/VIAA/3/19/514 "Effective Maritime Spatial Planning Regulation Framework and Implementation Challenges and Best Practice Examples for the Context of the Baltic Sea"), funded by the European Regional Development Fund (project No. 1.1.1.2/16/I/001). 


\section{References}

1. Commission of the European Communities. (2009). Concerning the EU Strategy for the Baltic Sea Region. Communication from the Commission to the European Parliament, the Council, the European Economic and Social Committee and the Committee of the Regions. COM(2009) 248 final.

2. Directive 2014/89/EU. Establishing a framework for Maritime Spatial Planning. European Parliament, Council.

3. Directive 2008/56/EC. Marine Strategy Framework Directive. European Parliament, Council.

4. ESPON. (2020). Maritime spatial planning and land-sea interactions. Policy Brief.

5. European Commission. (2017). Maritime Spatial Planning: Addressing Land-Sea Interaction. A briefing paper.

6. European MSP Platform. (n.d.). MSP in the EU. Countries. https://www.mspplatform.eu/msp-practice/countries

7. Frederiksen, P., Morf, A., von Thenen, M., Armoskaite, A., Luhtala, H., Schiele, K.S., Strake, S., \& Hansen, H.S. (2021). Proposing an ecosystem-services based framework to assess sustainability impacts of maritime spatial plans (MSP-SA). Ocean and Coastal Management, 208, Article 105577.

8. Jones, P.J.S., Lieberknecht, L.M., \& Qiu, W. (2016). Marine spatial planning in reality: Introduction to case studies and discussion of findings. Marine Policy, 71, 256-264.

9. Kidd, S., Jay, S., Robinson, L., Shaw, D., Jones, H., Pascual, M., Zonta, D., de Vet, J.M., Abhold, K., Kruger, I., McGlade, K., Malak, D.A., \& Sanchez, A. (2020). ESPON. MSP-LSI - Maritime Spatial Planning and Land-Sea Interactions. Targeted Analysis. Final Report.

10. Kidd, S., Jones, H. \& Jay, S. (2019). Taking Account of Land-Sea Interactions in Marine Spatial Planning. In J. Zaucha, \& K. Gee (Eds.), Maritime Spatial Planning: Past, Present, Future (pp. 245-270). Springer.

11. Long, R.D., Charles, A., \& Stephenson, R.L. (2015). Key principles of marine ecosystem-based management. Marine Policy, 57, 53-60.

12. Ministry of Environmental Protection and Regional Development of the Republic of Latvia. (2019). Guidelines for Planning Marine Coastal Waters and the Adjacent Land Areas at the Local Level. Pan Baltic Scope.

13. Morf, A. (ed.), Cedergren, E., Gee, K., Kull, M., \& Eliasen, S. (2019). Lessons, stories and ideas on how to integrate Land-Sea Interactions into MSP. Nordregio. Pan Baltic Scope.

14. O'Hagan, A.M., Paterson, S., \& Le Tissier, M. (2021). Addressing the tangled web of governance mechanisms for land-sea interactions: Assessing implementation challenges across scales. Marine Policy, 112, Article 103715.

15. Pyc, D. (2019). Implementation of marine spatial planning instruments for sustainable marine governance in Poland. TransNav, 13(2), 311-316.

16. Piwowarczyk, J., Gee, K., Gilek, M., Hassler, B., Luttmann, A., Maack, L., Matczak, M., Morf, A., Saunders, F., Stalmokaite, I., \& Zaucha, J. (2019). Insights into integration challenges in the Baltic Sea Region marine spatial planning: Implications for the HELCOM-VASAB principles. Ocean and Coastal Management, 175, 98-109. 
17. Saunders, F., Gilek, M., Ikauniece, A., Tafon, R.V., Gee, K., \& Zaucha, J. (2020). Theorizing social sustainability and justice in marine spatial planning: democracy, diversity, and equity. Sustainability, 12, 2560.

18. Schlüter, A., Van Assche, K., Horindge, A.-K., \& Vaidianu, N. (2020). Land-sea interactions and coastal development: An evolutionary governance perspective. Marine Policy, 112, Article 103801.

19. Soininen, N., \& Hassan, D. (2019). Marine spatial planning and the new frontiers of marine governance. In D. Hassan, \& S. Karim (Eds.), International Marine Environmental Law and Policy (pp. 101-120). Routledge. ISBN: 9781138651135

20. Stelzenmüller, V., Cormier, R., Gee, K., Shucksmith, R., Gubbins, M., Yates, K. L., Morf, A., Nic Aonghusa, C., Mikkelsen, E., Tweddle, J.F., Pecceu, E., Kannen, A., \& Clarke, S.A. (2021). Evaluation of marine spatial planning requires fit for purpose monitoring strategies. Journal of Environmental Management, 278(2), Article 111545.

21. UN Committee of Experts on Public Administration. (2019). Report on the eighteenth session (8-12 April 2019). E/2019/44-E/C.16/2019/8. https://undocs.org/en/e/c.16/2019/8

22. UN Economic and Social Council. (2018). Principles of effective governance for sustainable development. E/2018/44-E/C.16/2018/8, para. 31. Supplement No. 24. https://publicadministration.un.org/Portals/1/Images/CEPA/Principles_of_effective_go vernance_english.pdf

23. Van Assche, K., Hornidge, A.-K., Schlüter, A., \& Vaidianu, N. (2020). Governance and the coastal condition: Towards new modes of observation, adaptation and integration. Marine Policy, 112, Article 103413.

24. VASAB Secretariat. (2021a, July 15). $4^{\text {th }}$ Baltic MSP Forum. Workshop 6: Land-sea Interactions and Values of Local Community [Video]. YouTube.

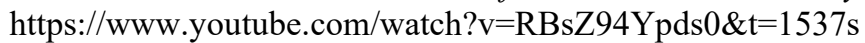

25. VASAB Secretariat. (2021b, July 15). $4^{\text {th }}$ Baltic MSP Forum. Workshop 7: Multi-level governance for the coast and the sea - the new normal? [Video]. YouTube. https://www.youtube.com/watch?v=CvjZOksbJWM

26. VASAB Secretariat. (2021c, July 13). $4^{\text {th }}$ Baltic MSP Forum - Panel Discussion on Regional Frameworks [Video]. $\quad$ YouTube. https://www.youtube.com/watch?v=7DKEZ3v66XQ\&t=1054s

27. Zaucha, J. (2014). Sea basin maritime spatial planning: A case study of the Baltic Sea region and Poland. Marine Policy, 50, 34-45. 